\title{
Direct Estimation of Local pH Change at Infection Sites of Fungi in Potato Tubers
}

\author{
R. Tardi-Ovadia, R. Linker, and L. Tsror (Lahkim)
}

First and second authors: Faculty of Civil and Environmental Engineering, Technion-Israel Institute of Technology. Haifa 32000, Israel; and third author: Department of Plant Pathology \& Weed Research, Institute of Plant Protection, Agricultural Research Organization, Gilat Research Center, M.P. Negev 85280, Israel.

Accepted for publication 16 September 2016.

\begin{abstract}
Fungi can modify the $\mathrm{pH}$ in or around the infected site via alkalization or acidification, and $\mathrm{pH}$ monitoring may provide valuable information on host-fungus interactions. The objective of the present study was to examine the ability of two fungi, Colletotrichum coccodes and Helminthosporium solani, to modify the $\mathrm{pH}$ of potato tubers during artificial inoculation in situ. Both fungi cause blemishes on potato tubers, which downgrades tuber quality and yield. Direct visualization and estimation of $\mathrm{pH}$ changes near the inoculation area were achieved using $\mathrm{pH}$ indicators and image analysis.

The results showed that the $\mathrm{pH}$ of the area infected by either fungus increased from potato native $\mathrm{pH}$ of approximately 6.0 to 7.4 to 8.0. By performing simple analysis of the images, it was also possible to derive the growth curve of each fungus and estimate the lag phase of the radial growth: 10 days for $C$. coccodes and 17 days $H$. solani. In addition, a distinctive halo (an edge area with increased $\mathrm{pH}$ ) was observed only during the lag phase of $H$. solani infection. $\mathrm{pH}$ modulation is a major factor in pathogen-host interaction and the proposed method offers a simple and rapid way to monitor these changes.
\end{abstract}

Tubers of the potato plant (Solanum tuberosum) carry many seedand soilborne pathogens that affect quality and yield (Tsror (Lahkim) et al. 1999). Silver scurf, caused by Helminthosporium solani, and black dot, caused by Colletotrichum coccodes, produce tuber blemishes and affect processing and fresh-market trade (Mattupalli et al. 2013). According to the British Potato Council estimations, direct annual losses associated with these diseases is up to $£ 5$ million in the United Kingdom alone (Lees and Hilton. 2003). The pathogens can penetrate the tubers during growth or during harvest and handling. Although $C$. coccodes can colonize all underground parts (daughter tubers, stolons, and roots), basal stems, and foliage (Tsror (Lahkim) and Peretz-Alon 2004), H. solani is considered to be a storage disease and the symptoms appear only on the tuber surface, localized to the periderm (Errampalli et al. 2001). Symptoms of silver scurf and black dot are frequently confused due to the similarity of blemishes caused on the periderm, and because they may be present simultaneously on the same tuber (Mattupalli et al. 2013).

Examination of tubers with a hand lens or microscope is required to observe the characteristic black microsclerotia of C. coccodes, or typical conidiophores and conidia of $H$. solani (Errampalli et al. 2001; Tsror (Lahkim) and Peretz-Alon 2004). However, these structures are not always present, and additional diagnostic methods must be applied (isolation on selective media, serology, or molecular techniques).

Environmental $\mathrm{pH}$ is one of the key physiochemical factors that determine survival and control growth and development in fungi (Bassil et al. 2012; Wasantha Kumara and Rawal 2008; Prusky et al. 2001). Enzymes essential for fungal infection are mainly extracellular, and $\mathrm{pH}$ regulation ensures that extracellular enzymes, including amylase, cellulose, lipase, pectinase, and protease, are secreted under optimal conditions for their activity (Abe et al. 2015; Cotton et al. 2003; Drori et al. 2003; Maccheroni et al. 2004). For example, pectate lyase

Corresponding author: R. Linker; E-mail address: linkerr@tx.technion.ac.il

(C) 2017 The American Phytopathological Society is secreted by $C$. gloeosporioides at $\mathrm{pH}$ values higher than 5.8, even though it is already expressed at $\mathrm{pH}$ values of 5.1 (Prusky et al. 2001).

Fungi can, to some extent, modify the $\mathrm{pH}$ in or around the infected site via alkalization or acidification. For instance, Colletotrichum and Alternaria genera alkalize their environment, whereas Penicillium spp. and Sclerotinia and Botrytis genera acidify it (Davidzon et al. 2010). Alkalinization by fungi has been reported in a number of crops: in avocado infected by $C$. gloeosporioides and in tomato and apple fruit infected by Colletotrichum genera (Alkan et al. 2008). In contrast, colonization of mango and grape by Phomopsis mangiferae was accompanied by local acidification of the host tissue, from 5.1 to 3.8 in mango and from 4.1 to 2.5 in grape (Davidzon et al. 2010). It has been suggested that ammonification and alkalization are correlated (Alkan et al. 2008). Ammonification of the infected site affects various processes such as enzyme secretion and virulence increase (Prusky and Lichter 2007), activation of appressorium formation and differentiation (Miyara et al. 2010), and activation of quiescent infections in postharvest pathogens (Prusky et al. 2013).

$\mathrm{pH}$ alkalization at the cellular level, using a $\mathrm{pH}$-sensitive fluorophore in confocal scanning microscopy, was observed within and in proximity to fungal infection structures of $C$. acutatum in almond tissue (Diéguez-Uribeondo et al. 2008). Furthermore, Bi et al. (2016) reported that differential $\mathrm{pH}$ modulation by fruit fungal pathogens is a host-dependent mechanism that is affected by host sugar content, which modulates environmental $\mathrm{pH}$ and enhances fruit colonization.

The average $\mathrm{pH}$ value of potato tubers has been estimated to be 6.0 , and long storage generally did not have a significant effect on $\mathrm{pH}$ of the tubers of wild species (Kiszonas and Bamberg 2010). Nitzan and Tsror Lahkim (2003) reported that the optimal $\mathrm{pH}$ value for $C$. coccodes isolates in vitro growth ranged from 6.0 and 7.0, depending on the isolate. This fact can explain the necessity of ammonia secretion into the local surroundings of the fungus during infection (Alkan et al. 2008).

The available methods, either direct or indirect, for measuring $\mathrm{pH}$ in fruit and vegetables include potentiometric ( $\mathrm{pH}$ electrode) and optical methods ( $\mathrm{pH}$ indicator and $\mathrm{pH}$ test strips). The optical methods are based on visual and photometric analysis of $\mathrm{pH}$-dependent color 
changes, which are evaluated by visual comparison of color against a reference color scale. However, its precision is only sufficient to provide a rough estimate. The most common method for accurate $\mathrm{pH}$ measurement is by $\mathrm{pH}$ electrodes (Kurkdjian and Guern.1989). Unfortunately, insertion of conventional pH electrodes (either "flat" or "spear") and microelectrodes is not feasible in all fruit and vegetables, due to their diversity in texture and structure. In particular, insertion of microelectrodes into potato tubers is practically impossible due to their rigid structure. Consequently, at present, there is no available method for measuring $\mathrm{pH}$ in potato tuber flesh which does not require a primary preparation procedure that destroys the tuber tissue (i.e., indirect homogenization method) (Alkan et al. 2008.)

Tuber wounds or skin injuries may accelerate the infection process. The inner tissues of the injured tubers, exposed to the external environment, may become desiccated or infected by pathogens,

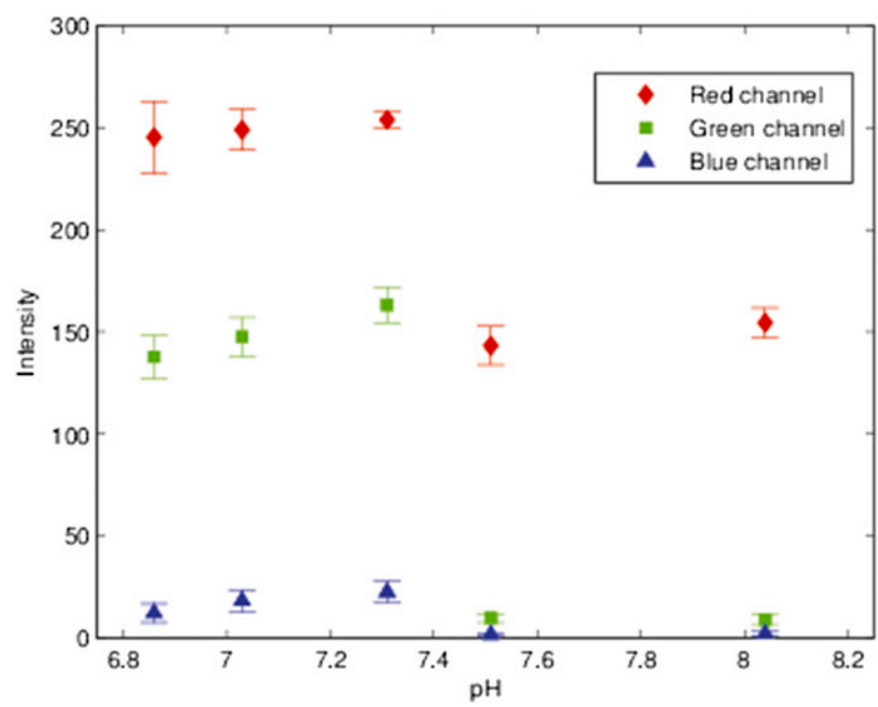

Fig. 1. RGB value intensity versus $\mathrm{pH}$ in $0.01 \%$ phenol red agar plates. Error bars correspond to the standard deviation within the 300-by-300-pixel region of interest. creating lesions within days or weeks (Barth et al. 2010). The main defense mechanism of potato tubers against water loss, mechanical damage, and pathogens consists of a specialized suberin-rich layer, called the native periderm (Ginzberg 2008).

The objective of the present study was to develop a method that enables direct visualization and estimation of $\mathrm{pH}$ change on the potato tuber surface during artificial inoculation (in situ), based on $\mathrm{pH}$ indicator and image analysis.

\section{MATERIALS AND METHODS}

In order to study the difference between the effect of fungal infection and skin injuries on $\mathrm{pH}$ change, and to rule out the possibility that observed $\mathrm{pH}$ changes were associated with the wound-periderm formation and suberization process itself rather than with the pathogen infection, the experiments were divided into two pathways: one addressing biotic infection (artificial fungal inoculation) and a second addressing abiotic injury, as further described below. The study was conducted with two fungi which have similar visual symptoms (namely, $C$. coccodes and $H$. solani) originally isolated from potato tubers with typical symptoms of each disease.

Tuber inoculation, treatment, and infection. Preliminary preparation of potato tubers. All experiments were conducted with 'Winston' potato. Tubers were stored at 4 to $8^{\circ} \mathrm{C}$ and transferred to room temperature prior to the experiments. Tubers were surface disinfected with a sterilant chlorox solution $(0.15 \%$ [vol/vol] $)$ for $10 \mathrm{~min}$, washed twice with sterile deionized water, air dried for $1 \mathrm{~h}$ in a petri dish, cut with a sterile scalpel to equally sized slices 1 to $1.5 \mathrm{~cm}$ thick, and further air dried in a petri dish.

Artificial inoculation with $\mathrm{C}$. coccodes and $\mathrm{H}$. solani. Our efforts to inoculate a whole tuber did not yield consistent results; therefore, we adapted the "hyphal mat infection method" (Alkan et al. 2008) to inoculate the tuber flesh, and established a homogenous system with consistent and reproducible conditions. Potato slices were prepared on day zero prior to inoculation. The inoculation with $C$. coccodes or $H$. solani was done by placing a plug ( 2 by $2 \mathrm{~mm}$ ) of 3 - to 5-day-old culture fungal mycelium (grown on potato dextrose agar) (Oxoid) on the potato disc. The inoculated discs were incubated in sterile petri dishes at $25^{\circ} \mathrm{C}$ for the entire experimental period. Noninoculated

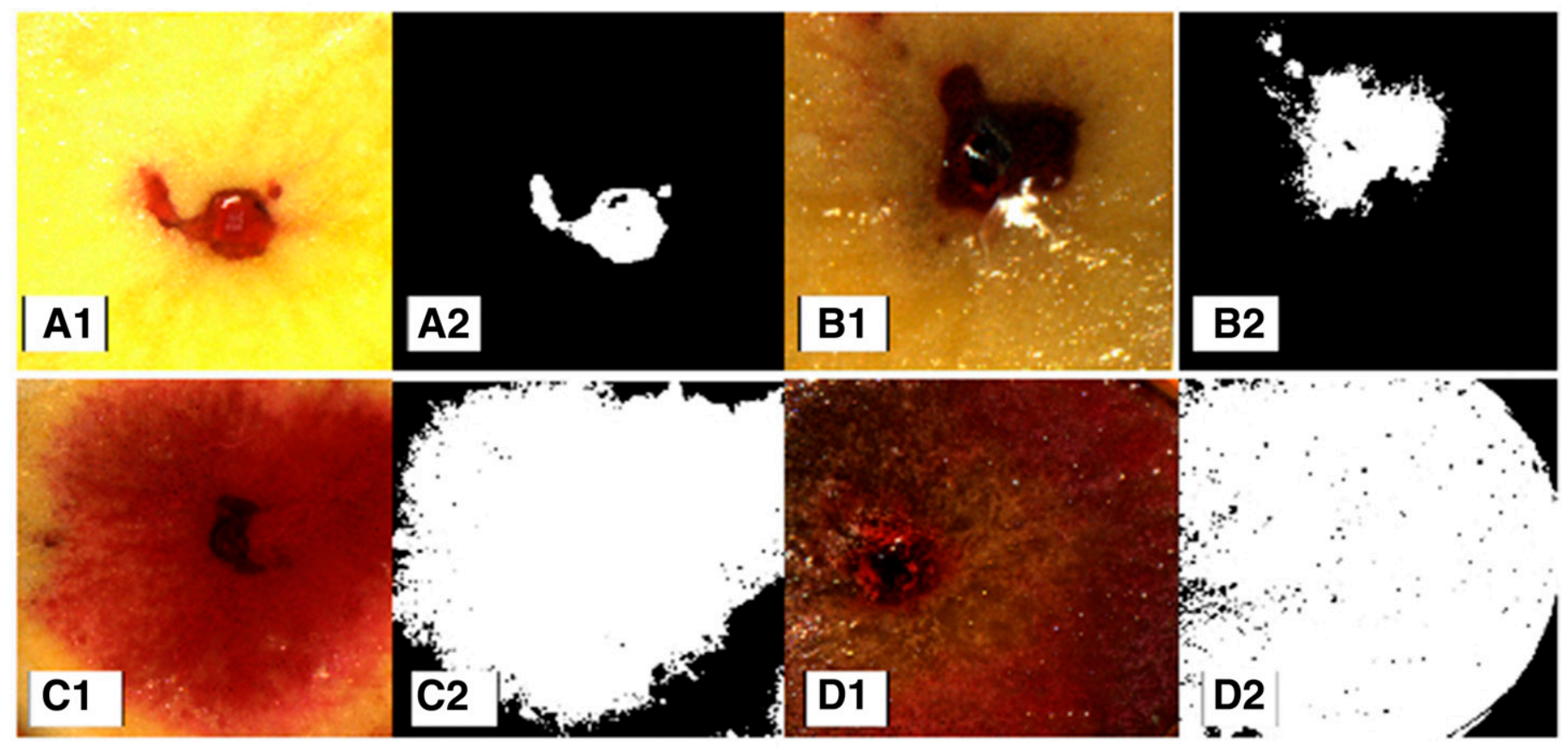

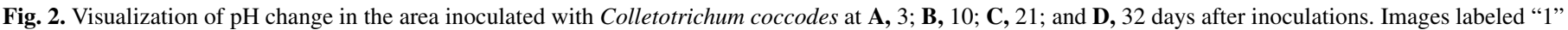

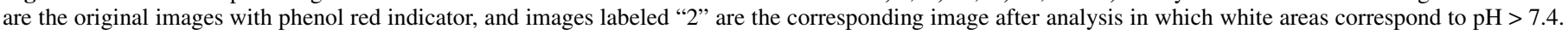


potato discs (controls) were incubated under similar conditions. Examination of the inoculated potato discs was carried out twice a week. At each sampling date, 10 slices from each treatment were used for examination: 9 samples for each $\mathrm{pH}$ indicator treatment (3 triplicates per $\mathrm{pH}$ indicator) and 1 slice for control (noninoculated). For each experiment, a different set of indicators was used, as explained below.

Abiotic treatment (wound-periderm formation and suberization process). To evaluate whether the formation of wound periderm after skin injuries has an impact on $\mathrm{pH}$, slices of potato tubers were incubated in sterile petri dishes at $25^{\circ} \mathrm{C}$ (the optimal temperature for suberization) (Ginzberg 2008). The experiment was conducted for 14 days in order to fully complete the suberization process during wound periderm formation.

$\mathrm{pH}$ indicators. Base on previous reports only on the ability of C. coccodes to change ambient $\mathrm{pH}$ in other crops, three $\mathrm{pH}$ indicators were chosen to cover the whole range of $\mathrm{pH}$ values relevant to fungal infection: $0.01 \%(\mathrm{wt} / \mathrm{vol})$ thymol blue solution (Sigma-Aldrich) (transition zone: 1.2 to 2.8 and 8.0 to 9.2 ), $0.01 \%$ (wt/vol) phenol red solution (Sigma-Aldrich) (transition zone: 6.8 to 8.2 ), and $0.01 \%$ (wt/vol) phenolphthalein solution (Sigma-Aldrich) (transition zone: 8.2 to 12 ). For abiotic injury experiments, the following indicators
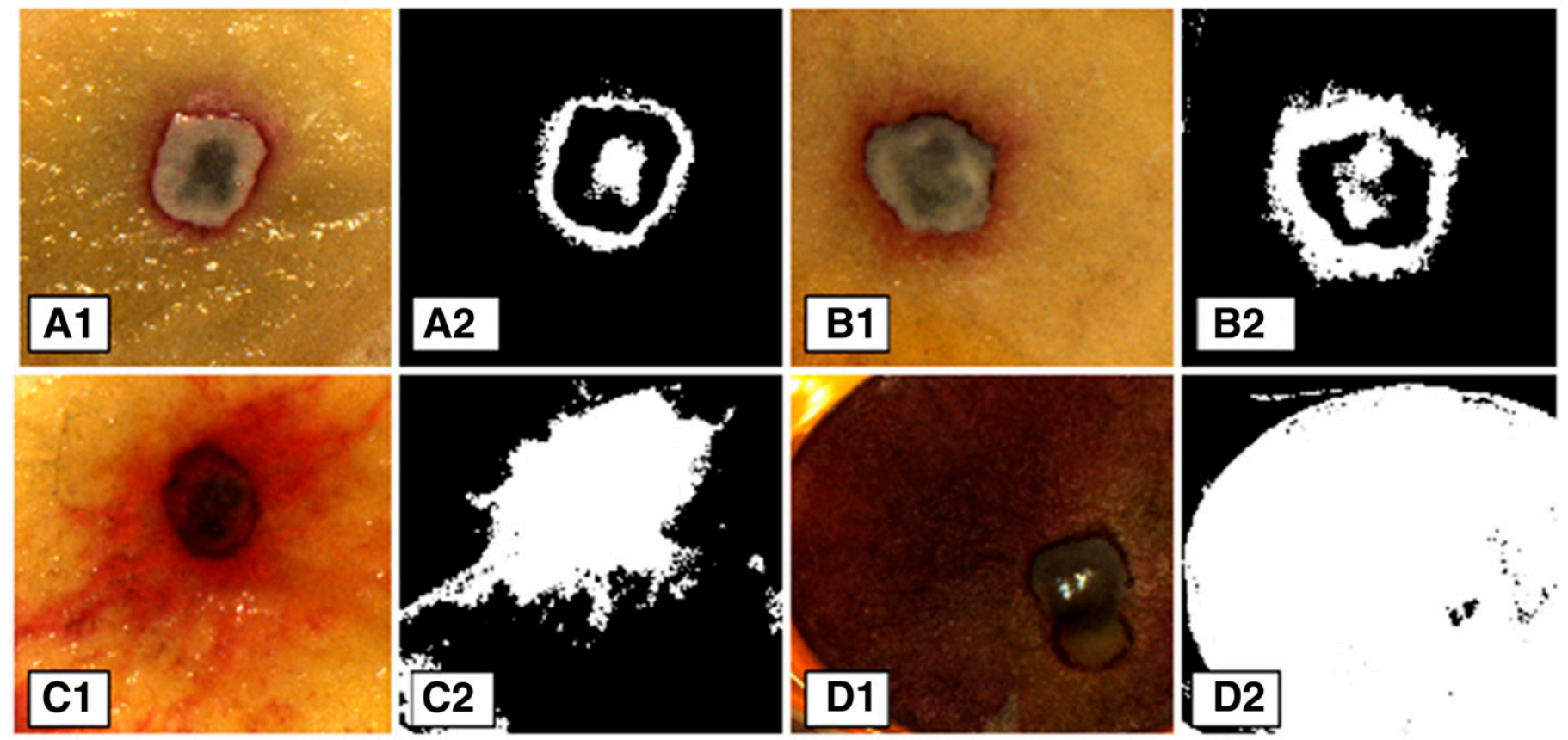

Fig. 3. Visualization of $\mathrm{pH}$ change in the area inoculated with Helminthosporium solani at $\mathbf{A}, 3 ; \mathbf{B}, 17 ; \mathbf{C}, 32$; and $\mathbf{D}, 45$ days after inoculations. Images labeled "1" are the original images with phenol red indicator, and images labeled "2" are the corresponding image after analysis in which white areas correspond to $\mathrm{pH}>7.4$.
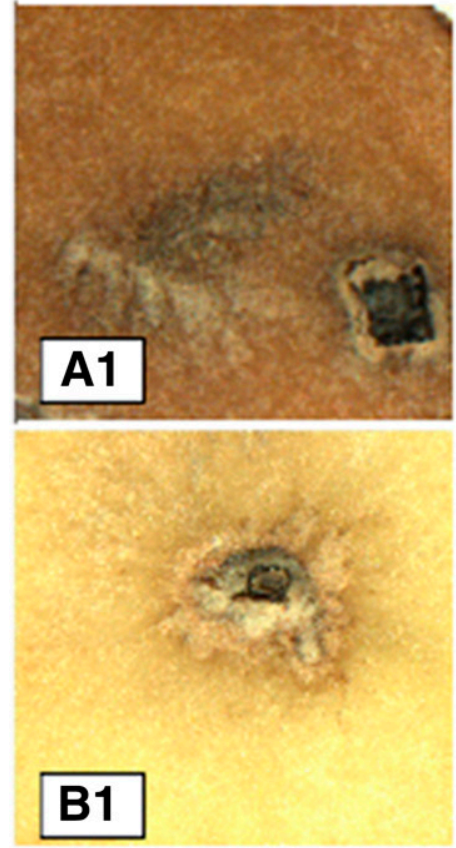
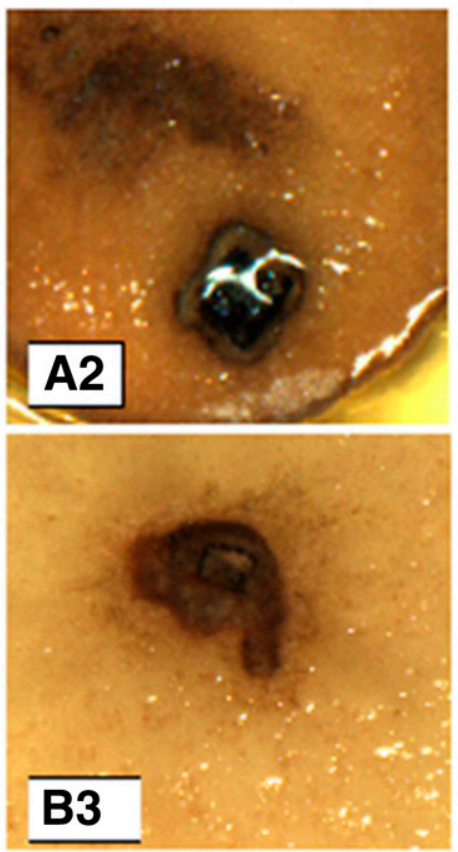
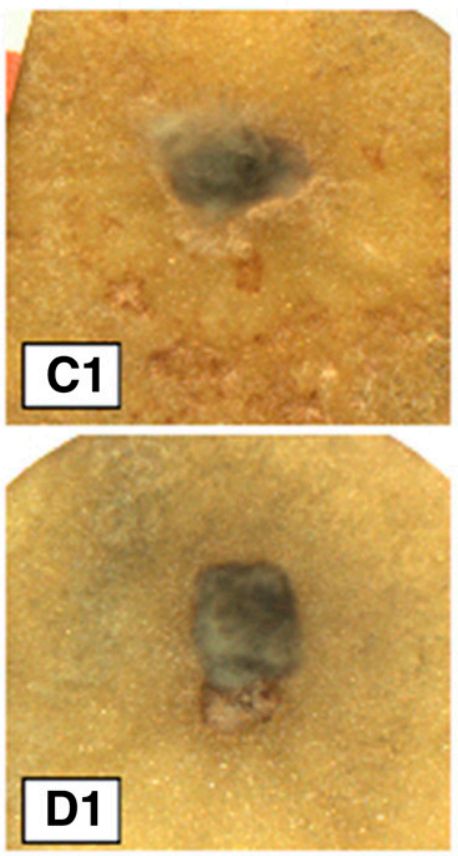
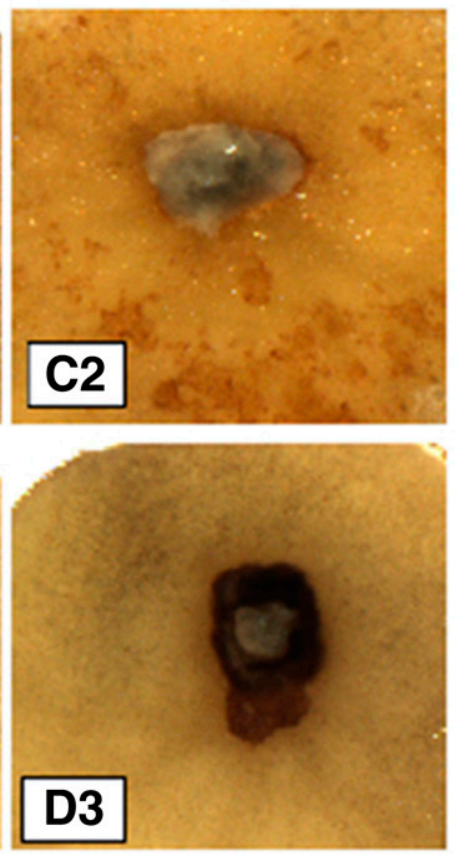

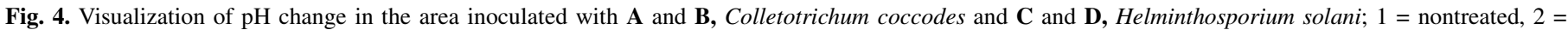
treated with thymol blue indicator, and $3=$ treated with phenolphthalein indicator. 
were used: $0.01 \%$ (wt/vol) bromocresol purple (Sigma-Aldrich) (transition zone: 5.2 to 6.8$), 0.01 \%$ (wt/vol) phenol red solution (Sigma-Aldrich) (transition zone: 6.8 to 8.2 ), and $0.01 \%$ (wt/vol) Congo red solution (Sigma-Aldrich) (transition zone: $\mathrm{pH} 3.0$ to 5.2). $p H$ visualization. In order to visualize $\mathrm{pH}$ shift in the infected area, $\mathrm{pH}$ indicator solution was placed on the entire potato disc using a sterile pipette and the sample was placed underneath an imaging system consisting of a CCD color camera (Basler Scout) equipped with an $\mathrm{f}=35 \mathrm{~mm} / \mathrm{F} 1.4$ Navitar lens. Each image included a $\mathrm{pH}$ measuring litmus paper previously soaked in distilled water, and the pixels of this region were used to verify that there was no significant fluctuation of the illumination. To establish a correlation between $\mathrm{pH}$ and apparent pixel color in the images, $0.01 \%$ phenol red agar plates $(1.5 \%$ agar) with the following $\mathrm{pH}$ values were prepared: $6.9,7.0,7.3,7.5$, and 8.0. The plates were placed under the imaging system described above and several images of each plate were captured. In each image, the pixels of a region of interest (ROI) of 300 by 300 pixels were extracted and the mean and standard deviation of the three color components (RGB) were calculated.

Measurement of radial infected zone (decayed zone). Fungus growth is expressed in terms of the radius of a hypothetical circle which would have an area equal to that of the area of elevated $\mathrm{pH}$.

\section{RESULTS}

pH visualization using the imaging system. A sharp decrease of the green and red components occurred in the ROI of the agar plates between $\mathrm{pH} 7.3$ and 7.5 (Fig. 1). The blue component had much smaller values with relatively larger standard deviation;

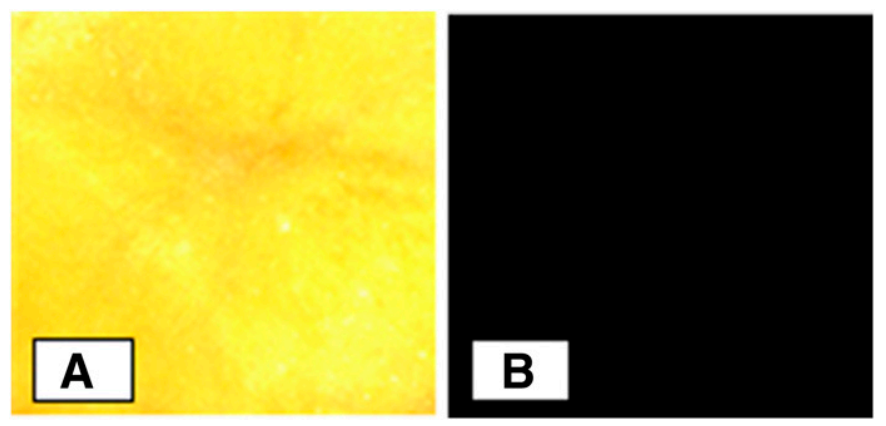

Fig. 5. A, Noninoculated potato discs with phenol red indicator after 10 days of suberization. B, Image after analysis; the absence of white pixels in the right image indicates that the $\mathrm{pH}$ was below 7.4 in the whole area.

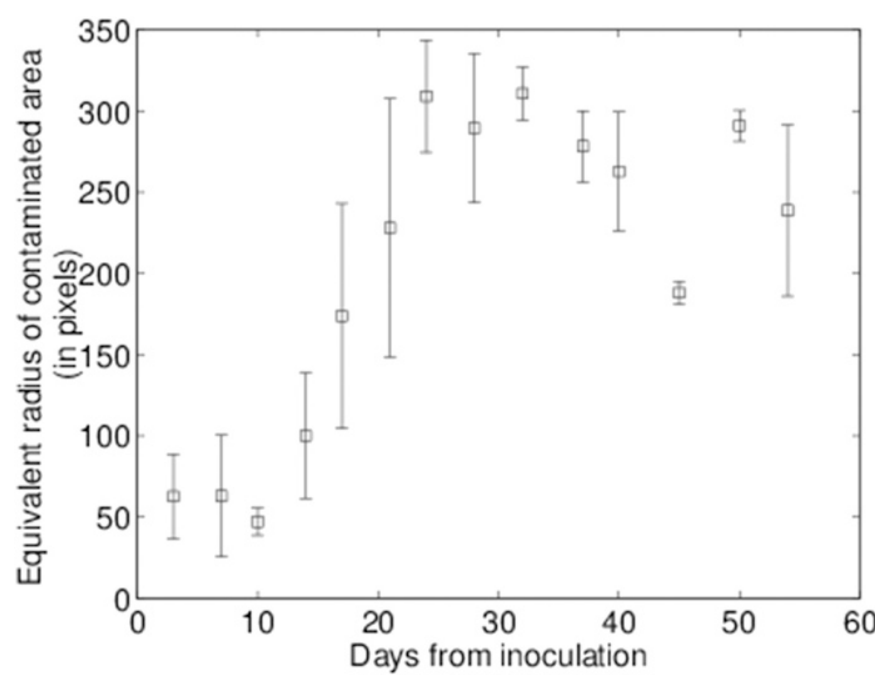

Fig. 6. Time evolution of the equivalent radius of the area inoculated with $\mathrm{Col}$ letotrichum coccodes. Error bars correspond to standard deviation of three samples. therefore, this component was not used in the analysis. Based on the data presented in Figure 1, pixels with green value lower than 70 and blue value lower than 220 were considered to correspond to $\mathrm{pH}$ higher than 7.4 while the other pixels were considered to correspond to $\mathrm{pH}$ values lower than 7.4.

Visualization of $\mathrm{pH}$ change in the area inoculated with C. coccodes and $\boldsymbol{H}$. solani. In order to detect the effect of growth on $\mathrm{pH}$ value at the infected area using $\mathrm{pH}$ indicators, the inoculated potato tuber discs were visualized using the imaging system, and the images were processed using the RGB thresholds determined above.

For both fungi, the $\mathrm{pH}$ shift stopped abruptly at the margin of the lesion (Figs. 2 and 3). A correlation between the morphological symptoms of the infected area and the visualized $\mathrm{pH}$ was observed. No color change was observed using thymol blue and phenolphthalein indicators (Fig. 4). Therefore, combining phenol red and thymol blue measurements showed that $\mathrm{pH}$ in the infected areas was between 7.4 and 8.0. No change in $\mathrm{pH}$ value was observed in the noninoculated control during the whole experimental period (Fig. 5).

From binary images such as those shown in Figures 2 and 3, it is possible to estimate the radius equivalent to the area infected by the fungus or, more precisely, the area in which the $\mathrm{pH}$ is affected by the fungal activity (Figs. 6 and 7 for $C$. coccodes and $H$. solani, respectively). The lag phase of the radial growth for $C$. coccodes and $H$. solani lasted 10 and 17 days, respectively. Moreover, $\mathrm{pH}$ visualization revealed differences in the pathogen-host interaction between the two fungi during the initial lag phase of infection: C. coccodes affected $\mathrm{pH}$ in the whole infected area, whereas $H$. solani affected $\mathrm{pH}$ only at the edge of the infected area, creating a clearly defined halo (region with $\mathrm{pH}>7.4$ ). This phenomenon was observed during the first 17 days postinoculation (Fig. 3A and B).

Visualization of $\mathbf{p H}$ change during wound healing. In order to investigate whether the $\mathrm{pH}$ value of the wounded tissue was affected by the healing process, several $\mathrm{pH}$ indicators were used to cover acidic, neutral, and alkaline $\mathrm{pH}$. No change in $\mathrm{pH}$ value was observed during the wound healing process (Fig. 8A, B, and C: phenol red, bromocresol purple, and Congo red, respectively).

\section{DISCUSSION}

$\mathrm{pH}$ monitoring provides valuable information on host-fungus interactions because $\mathrm{pH}$ is one of the main factors controlling fungal growth and has a crucial role in fungal establishment. The $\mathrm{pH}$ level prevailing in the host may cause activation from quiescence to an active infection (Prusky and Lichter 2007). These changes in host tissue activate transcription and secretion of fungal degradative

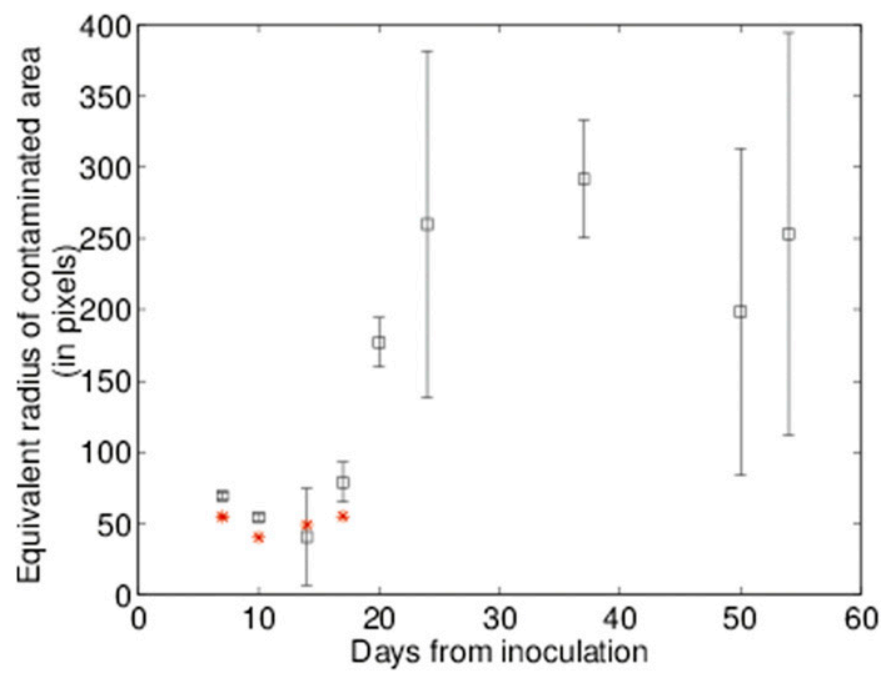

Fig. 7. Time evolution of the equivalent radius of the area inoculated with $\mathrm{Hel}$ minthosporium solani. For the first four sampling dates, the inner radius of the halo is also indicated. Error bars correspond to the standard deviation of three samples. 


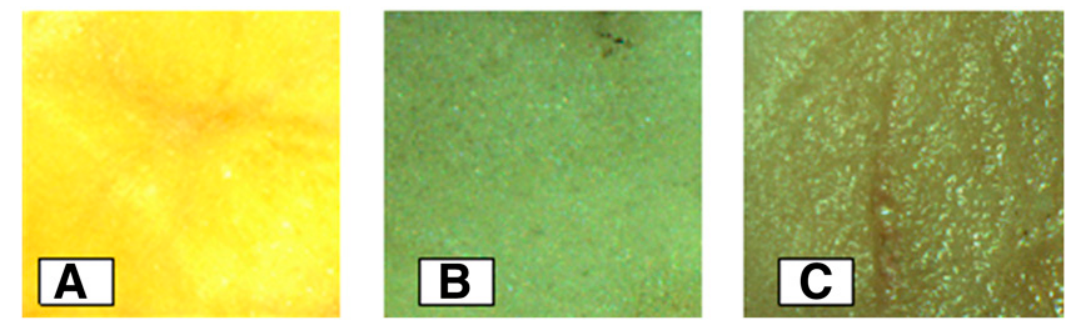

Fig. 8. Noninoculated potato disc suberization treated with indicator after 10 days of suberization: IA, phenol red; B, bromocresol purple; and $\mathbf{C}$, Congo red indicators.

enzymes. The ability of $C$. coccodes to cause alkalization has been previously reported, whereas no information about $H$. solani causing a shift in $\mathrm{pH}$ value at the infected site is available.

In the current study, $\mathrm{pH}$ visualization confirmed the ability of C. coccodes to alkalinize potato tuber surroundings, as previously reported for other crops (Prusky et al. 2001), indicating that alkalization also is a crucial preliminary stage (alkalization was observed 3 days postinoculation) for fungal establishment on potato. The $\mathrm{pH}$ in the infected area shifted in more than 1.4 units from the potato native average $\mathrm{pH}$ (Fig. 1). A correlation between the morphological disease symptoms of the infected area and the visualized $\mathrm{pH}$ was observed (Figs. 2 and 3 ). This is the first report on the ability of $H$. solani to cause alkalization of the infected area, similarly to $C$. coccodes. No change was observed using thymol blue and phenolphthalein indicators for both fungi (Fig. 4). An interesting phenomenon was observed during the first 17 days after inoculation (Fig. 3A and B): a halo (region with $\mathrm{pH}>7.4$ ) appeared at the margin of the lesion formed after inoculation with $H$. solani. This halo was most probably formed due to extracellular enzymes and byproducts secreted into the infected area around the lesions. These extracellular enzymes released by the hyphal tips diffuse out ahead of the fungus in order to disintegrate compounds into nutrients needed for growth. Therefore, it can be suggested that alkalization of the tissue may be one of the factors that contributes to $H$. solani virulence and may serve as a biochemical activator.

Expressing the expansion of the infected area in terms of its equivalent radius (Figs. 6 and 7) enables a more quantitative examination of the $\mathrm{pH}$ change pattern over time. Although only three replicates were done for phenol red indicator, the pattern was clear and very consistent, with three main phases: lag, logarithmic, and stationary phase. We can conclude that, as disease symptoms progressed, potato tuber flesh became more alkaline for both investigated fungi. Wound periderm formation and the suberization process did not cause $\mathrm{pH}$ change in the noninoculated discs (Figs. 5 and 8); thus, it can be concluded that $\mathrm{pH}$ alteration was caused only by fungal activity. This agrees with the findings of Alkan et al. (2008), who did not observe $\mathrm{pH}$ change and ammonia accumulation in tomato fruit. Because, in the present study, fungal inoculation was done on tuber flesh rather than on tuber skin, at this stage we can only speculate that the fungi's ability to alkalize their ambient $\mathrm{pH}$ will be preserved on the skin.

The proposed method could be applied to monitor $\mathrm{pH}$ changes caused by other microorganisms infecting potato tubers such as Rhizoctonia solani, the causal agent of black scurf (Gonzalez García et al. 2006) during disease establishment. This method could also be useful for screening disease-resistant cultivars, which suppress the development of silver scurf and black dot lesions.

This newly developed method is simple and does not require expensive equipment or chemicals, and can easily be applied to other $\mathrm{pH}$ ranges by selecting a $\mathrm{pH}$ indicator accordingly. It provides an alternative to (micro) electrodes-based measurements which cannot be performed in hard fruit and vegetables such as potato. However, its main limitation is that it provides only a rough estimate of $\mathrm{pH}$ and not the actual $\mathrm{pH}$ value (e.g., greater than or less than the indicator transition value). Still, application of several indicators minimizes the range of uncertainty.

\section{LITERATURE CITED}

Abe, C. A. L., Faria, C. B., de Castro, F. F., de Souza, S. R., Santos, F. C. D., da Silva, C. N., and Barbosa-Tessmann, I. P. 2015. Fungi isolated from maize (Zea mays L.) grains and production of associated enzyme activities. Int. J. Mol. Sci. 16:15328-15346.

Alkan, N., Fluhr, R., Sherman, A., and Prusky, D. 2008. Role of ammonia secretion and $\mathrm{pH}$ modulation on pathogenicity of Colletotrichum coccodes on tomato fruit. Mol. Plant-Microbe Interact. 21:1058-1066.

Barth, M., Hankinson, T. R., Zhuang, H., and Breidt, F. 2010. Microbiological spoilage of fruits and vegetables. Pages 135-183 in: Compendium of the Microbiological Spoilage of Foods and Beverages. W. H. Sperber and M. P. Doyle, eds. Springer, New York.

Bassil, E., Coku, A., and Blumwald, E. 2012. Cellular ion homeostasis: Emerging roles of intracellular $\mathrm{NHX} \mathrm{Na+/H+} \mathrm{antiporters} \mathrm{in} \mathrm{plant} \mathrm{growth}$ and development. J. Exp. Bot. 63:5727-5740.

Bi, F., Barad, S., Ment, D., Luria, N., Dubey, A., Casado, V., Glam, N., Mínguez, J. D., Espeso, E. A., Fluhr, R., and Prusky, D. 2016. Carbon regulation of environmental $\mathrm{pH}$ by secreted small molecules that modulate pathogenicity in phytopathogenic fungi. Mol. Plant Pathol. 17:1178-1195.

Cotton, P., Kasza, Z., Bruel, C., Rascle, C., and Fèvre, M. 2003. Ambient pH controls the expression of endopolygalacturonase genes in the necrotrophic fungus Sclerotinia sclerotiorum. FEMS Microbiol. Lett. 227:163-169.

Davidzon, M., Alkan, N., Kobiler, I., and Prusky, D. 2010. Acidification by gluconic acid of mango fruit tissue during colonization via stem end infection by Phomopsis mangiferae. Postharvest Biol. Technol. 55: 71-77.

Diéguez-Uribeondo, J., Förster, H., and Adaskaveg, J. E. 2008. Visualization of localized pathogen-induced $\mathrm{pH}$ modulation in almond tissues infected by Colletotrichum acutatum using confocal scanning laser microscopy. Phytopathology 98:1171-1178.

Drori, N., Kramer-Haimovich, H., Rollins, J., Dinoor, A., Okon, Y., Pines, O., and Prusky, D. 2003. External pH and nitrogen source affect secretion of pectate lyase by Colletotrichum gloeosporioides. Appl. Environ. Microbiol. 69:3258-3262.

Errampalli, D., Saunders, J. M., and Holley, J. D. 2001. Emergence of silver scurf (Helminthosporium solani) as an economically important disease of potato. Plant Pathol. 50:141-153.

Ginzberg, I. 2008. Wound-periderm formation. Pages 131-149 in: Induced Plant Resistance to Herbivory. A. Schaller, ed. Springer, Dordrecht, The Netherlands.

Gonzalez García, V., Portal Onco, M. A., and Rubio Susan, V. 2006. Review. Biology and systematics of the form genus Rhizoctonia. Span. J. Agric. Res. 4:55-79.

Kiszonas, A. M., and Bamberg, J. B. 2010. Survey of tuber pH variation in potato (Solanum) species. Am. J. Potato Res. 87:167-176.

Kurkdjian, A., and Guern, J. 1989. Intracellular pH: Measurement and importance in cell activity. Annu. Rev. Plant Biol. 40:271-303.

Lees, A. K., and Hilton, A. J. 2003. Black dot (Colletotrichum coccodes): An increasingly important disease of potato. Plant Pathol. 52:3-12.

Maccheroni, W., Jr., Araújo W. L. and Azevedo, J. L. 2004. Ambient pHregulated enzyme secretion in endophytic and pathogenic isolates of the fungal genus Colletotrichum. Sci. Agric. 61:298-302.

Mattupalli, C., Genger, R. K., and Charkowski, A. O. 2013. Evaluating incidence of Helminthosporium solani and Colletotrichum coccodes on asymptomatic organic potatoes and screening potato lines for resistance to silver scurf. Am. J. Potato Res. 90:369-377. 
Miyara, I., Shafran, H., Davidzon, M., Sherman, A., and Prusky, D. 2010. pH regulation of ammonia secretion by Colletotrichum gloeosporioides and its effect on appressorium formation and pathogenicity. Mol. Plant-Microbe Interact. 23:304-316.

Nitzan, N., and Tsror Lahkim L. 2003. Effect of temperature and pH on in vitro growth rate and sclerotial density of Colletotrichum coccodes isolates from different VCGs. Am. J. Potato Res. 80:335-339.

Prusky, D., Alkan, N., Mengiste, T., and Fluhr, R. 2013. Quiescent and necrotrophic lifestyle choice during postharvest disease development. Annu. Rev. Phytopathol. 51:155-176.

Prusky, D., and Lichter, A. 2007. Activation of quiescent infections by postharvest pathogens during transition from the biotrophic to the necrotrophic stage. FEMS Microbiol. Lett. 268:1-8.
Prusky, D., McEvoy, J. L., Leverentz, B., and Conway, W. S. 2001. Local modulation of host $\mathrm{pH}$ by Colletotrichum species as a mechanism to increase virulence. Mol. Plant-Microbe Interact. 14:1105-1113.

Tsror (Lahkim), L., Erlich, O., and Hazanovsky, M. 1999. The effect of Colletotrichum coccodes (Wallr.) on potato yield, tuber quality and stem colonization during spring and autumn. Plant Dis. 83:566-568.

Tsror (Lahkim), L., and Peretz-Alon, I. 2004. Control of silver scurf on potato by dusting or spraying seed tubers with fungicides before planting. Am. J. Potato Res. 81:291-294.

Wasantha Kumara, K. L., and Rawal, R. D. 2008. Influence of carbon, nitrogen, temperature and $\mathrm{pH}$ on the growth and sporulation of some Indian isolates of Colletotrichum gloeosporioides causing anthracnose disease of papaya (Carrica papaya L). Trop. Agric. Res. Ext. 11:7-12. 